\section{Effect of positively and negatively correlated shock and reward on acquisition in the runway*}

\author{
J. W. SCULL, University of Sussex, Brighton BN1 9QY, England \\ and \\ DONNA VECHSLER, Carleton University, Ottawa, Ont., Canada
}

Three groups of rats were given $50 \%$ reward in a straight runway, with two of the groups also having gradually increasing shock on $50 \%$ of the trials. One shock group was shocked on rewarded trials and the other on nonrewarded trials. Both shocked groups ran more slowly and retraced more than the partial reward group, and the group shocked on rewarded trials ran faster and retraced less than the group shocked on nonrewarded trials. These results were discussed in terms of counterconditioning.

When both intermittent reward and intermittent punishment are scheduled to be contingent on the same response, the correlation between the two events can be manipulated without affecting the frequencies of the two events. In free operant barpressing experiments, a positive correlation between reward and mild punishment has been found to result in a higher response rate than does a negative correlation (Murray \& Nevin, 1967; Williams \& Barry, 1966).

There is far less evidence, however, for this effect in discrete-trial instrumental learning. Fallon's (1968) first figure shows a difference in acquisition of discrete-trial barpressing between positively and negatively correlated groups, but he failed to give supporting statistics. Logan (1960), running rats in a runway, found that a positively correlated group ran slightly faster than a negatively correlated group, but the difference was not statistically reliable.

In the present experiment, three groups of partially rewarded rats were given either positively correlated shock, negatively correlated shock, or no shock in the goalbox of a runway in an attempt to reliably demonstrate effects of reward-punishment correlation in a discrete-trial situation.

SUBJECTS AND APPARATUS

Thirty male Wistar strain albino rats served as Ss. They were purchased from Woodlyn Farms, Guelph, Ont., Canada, and were 70 to 80 days old at the start of the experiment.

The runway was built of 1 -in. pine board and covered with 1/4-in. clear Plexiglas. It was 63 in. long, 3 in. wide, and 4 in. deep. The sides and bottom were lined with two aluminum plates. They had a 1/2-in. gap between them,

* This research was supported by Grant APA-72 from the National Research Council of Canada and Grant GB-3772 from the National Science Foundation. The experiment was run while both authors were at the University of Toronto. running the length of the runway, which kept them electrically isolated. The floor between the plates was painted white. A gray startbox, 10 in. long, was separated from one end of the runway by a clear plastic Hunter automated start door. An unpainted metal guillotine door was located $15 \mathrm{in}$. from the other end of the runway. Reward was delivered by a Ralph Gerbrands pellet dispenser into a 2-in.-square foodcup recessed into the end of the runway. Shocks were delivered across the two plates with a Grason-Stadler constant-current shock generator.

Photoelectric cells and lights were located at 1 -ft intervals along the length of the runway, and time to

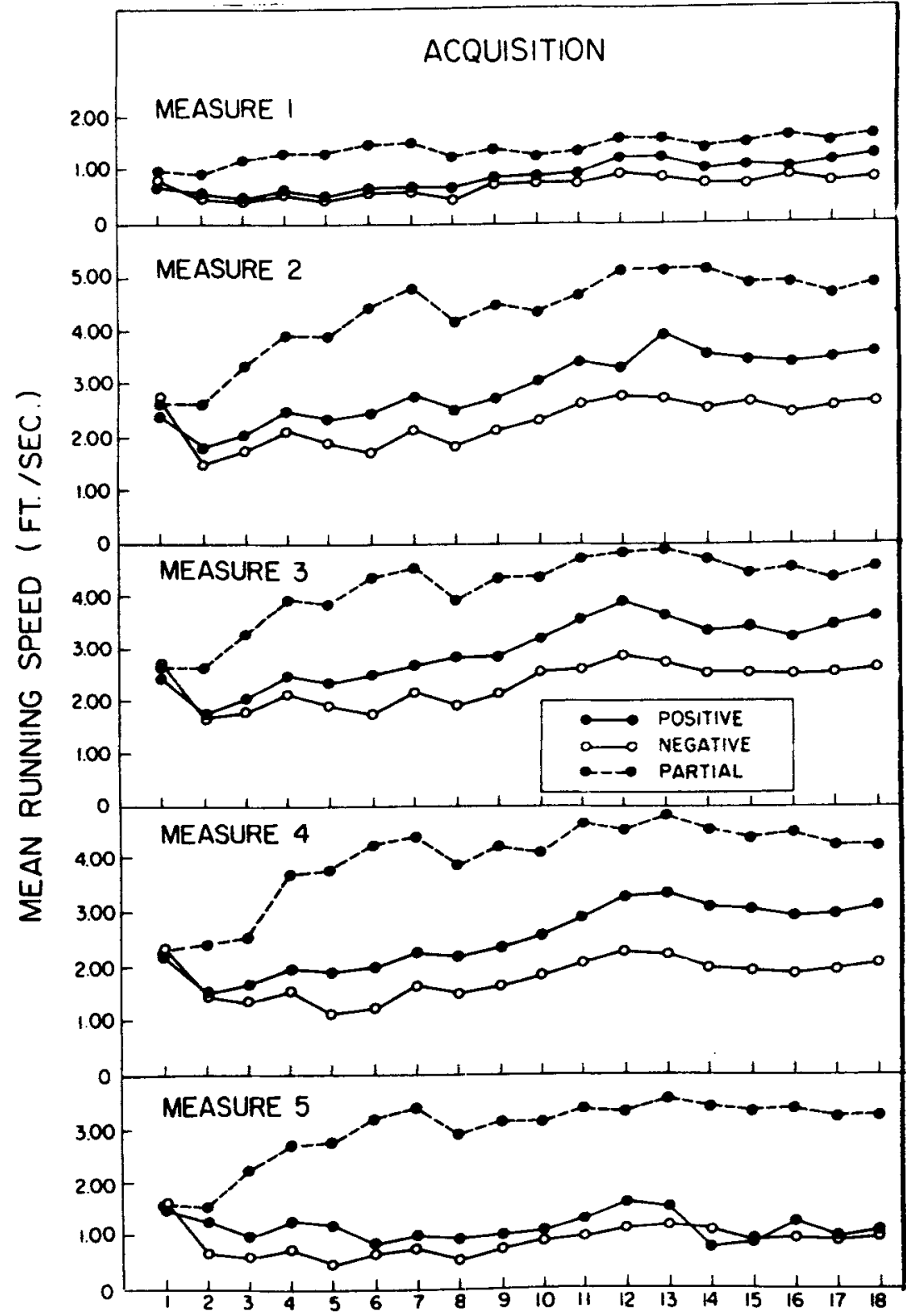

BLOCKS OF 8 TRIALS

Fig. 1. Running speeds for the three groups during training with intermittent reward and punishment. 


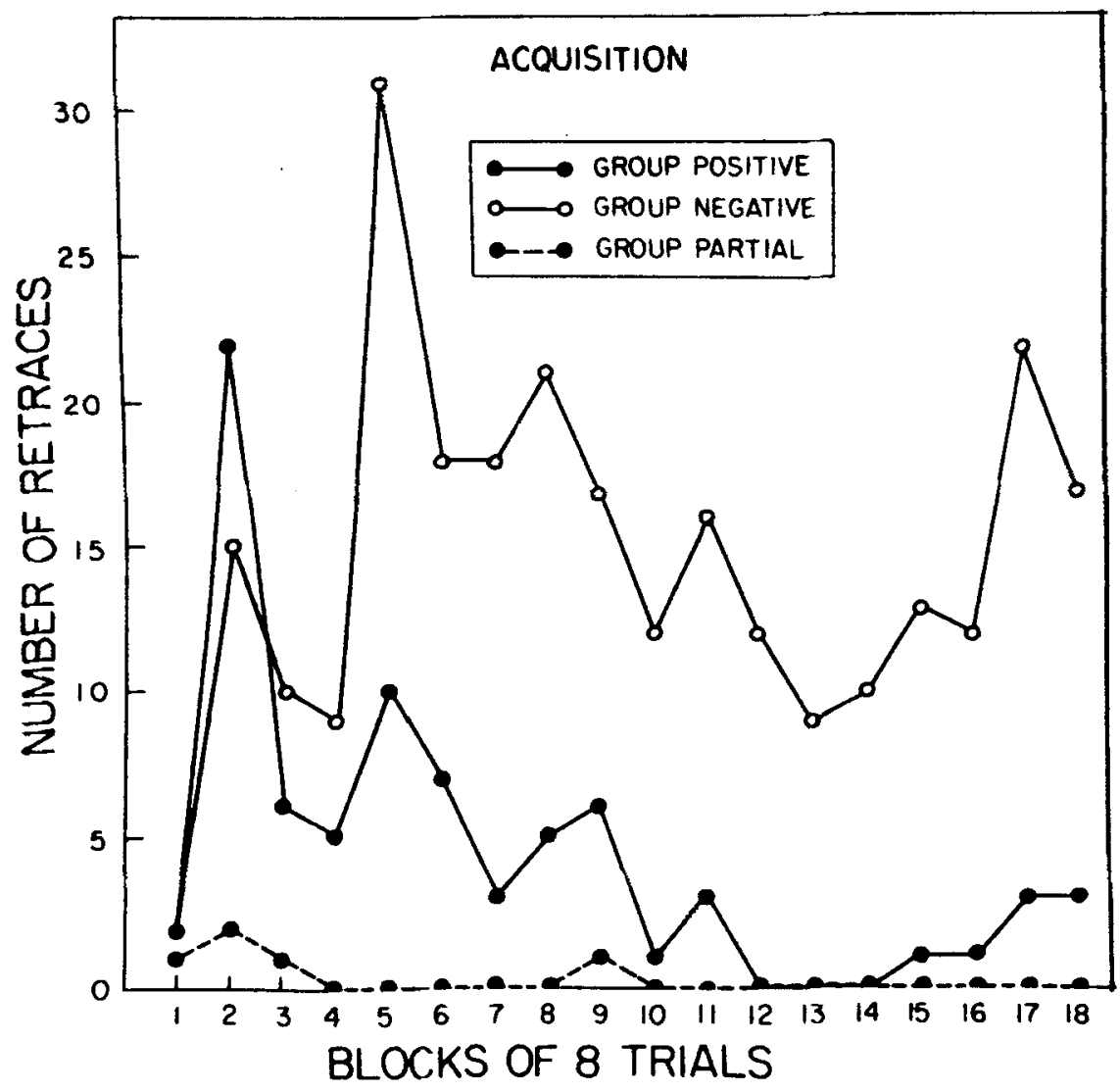

Fig. 2. Number of retraces in each 2-day block during training with intermittent reward and punishment.

traverse each segment was recorded with Standard electric timers. Relay equipment made operation of the pellet dispenser and shock generator contingent on the breaking of the last photobeam, $3 \mathrm{in}$. in front of the foodcup.

\section{PROCEDURE}

The Ss were maintained on ad lib water and $10 \mathrm{~g}$ of Purina Lab Chow per day for the entire experiment. After being handled briefly each day for 15 days prior to the start of the experiment, Ss were arbitrarily assigned to the three groups.

For the first 4 days of training, all Ss were rewarded on each trial and no shocks were given. For the next 36 days, all three groups were given $\mathbf{5 0 \%}$ reward. Group Pos received shocks on rewarded trials, Group Neg received shocks on nonrewarded trials, and Group Par was never shocked. Shock intensities were gradually increased as training progressed: $0.1 \mathrm{~mA}$ on the first 2 days, $0.2 \mathrm{~mA}$ on the next 21 days, and $0.25 \mathrm{~mA}$ for the last 13 days. The criterion for increasing the intensity at each stage was that all the trials on 1 day be completed in less than 30 sec. Reward was two $0.25 \mathrm{~g}$ Noyes pellets.

On each runway trial, $\mathrm{S}$ was placed in the startbox and the start door was opened as soon as he was oriented towards it. When $S$ broke the last photobeam, the metal retrace door closed behind him, and if a shock trial was scheduled, an immediate 0.5 -sec shock was delivered. On rewarded trials, the food dispenser was operated $0.5 \mathrm{sec}$ after the breaking of the last photobeam. Ss were run in rotation in a different random order each day but in the same order for the four trials of each day. The intertrial interval was never less than 25 min. During partial reinforcement, two randomly selected trials were rewarded each day. Time to traverse each 1-ft runway segment and each trial on which $S$ retraced was recorded.

Running times in each segment of the alley were converted to speeds and separate analyses of variance performed on each measure. The groups did not differ in performance during continuous reward pretraining, indicated by $F$ ratios less than unity for the group effect and the Group by Day interaction in all five measures. for all groups in all five runway segments for the partial reward-punishment phase. There were

\section{RESULTS}

Figure 1 shows mean running speeds significant effects in all measures of group and day, $\mathrm{p}<.01$, as well as a significant Group by Day interaction, $\mathrm{F}(68,918)=1.67,2.01,2.05,2.98$ 3.55, ps $<.01$. Analysis of simple effects within the interaction showed that for the first 2 days of training, there were no differences among groups. In all segments except the first, Group Par ran significantly faster than the other groups on every day after the second, ps $<.01$. For the last 14 days of training, Group Pos ran faster than Group Neg, $p<.01$, on almost every day in Segments 2,3 , and $4(11 / 14$ in Measure 2, 12/14 in Measure $3,14 / 14$ in Measure 4). There was a tendency for Group Pos to run faster than Group Neg in the first segment, but the difference was reliable only on 6 days. There was no systematic difference between Groups Pos and Neg in Measure 5.

Number of retraces per day during the partial reward-punishment phase are shown in Fig. 2. As soon as partial reward and punishment were introduced, the two punishment groups began retracing more than Group Par. After 4 days of punishment, Group Pos made fewer retraces than Group Neg. A Wilcoxon matched-pairs signed-ranks test comparing Groups Pos and Neg showed that they differed significantly, $\mathrm{T}=3, \mathrm{p}<.01$.

A positive correlation between shock and reward produced significantly faster running and less retracing than did a negative correlation. This extends the operant finding (Murray \& Nevin, 1967; Williams \& Barry, 1966) to a discrete-trial situation and verifies the suggestion of such a difference in other discrete-trial experiments (Fallon, 1968; Logan, 1960). Comparison with the partial reward control group shows that, under both conditions, the punishment markedly reduced the speed of running and increased the number of retraces. Murray \& Nevin (1967), on the other hand, found that positively correlated shock increased response rate over the level obtained in the absence of shock.

One interpretation of these results, proposed by Williams \& Barry (1966), is that some form of Pavlovian counterconditioning (Pavlov, 1927, pp. 29-31) occurred, which reduced the aversiveness of the shock. That is, in the positively correlated condition, the shock became a secondary reward through association with food. This decreased the aversiveness of the shock, just as secondary reward training increases the attractiveness of a neutral stimulus. A recent experiment by Fallon (1971) has apparently demonstrated a comparable 
process with reward as the conditional stimulus and shock as the unconditional stimulus. He found evidence that food followed by shock is functionally equivalent to a smaller amount of reward without shock.

Melvin \& Brown (1964) found that pairing a bright light with food decreased the latency of escape from the light. They suggested that instrumental responses incompatible with the escape response were conditioned to the light, thereby increasing escape latency. In the present experiment, this interpretation implies that for the positively correlated group, shock was an eliciting stimulus for a response compatible with running, while in the negatively correlated group, it was not. The retrace results of this experiment suggest that this may well be the case.

The clear superiority of the positively correlated group under the spaced-trial conditions of the present experiment provides support for associative interpretations like these two by largely ruling out explanations involving the aftereffects of shock and reward which could have applied to the free operant experiments.

\section{REFERENCES}

FALLON, D. Resistance to extinction following learning with punishment of reinforced and nonreinforced licking. Journal of Experimental Psychology, 1968, 76, 550-557.

FALLON, D. Increased resistance to extinction following punishment and reward: High frustration tolerance or low frustration magnitude? Journal of Comparative \& Physiological Psychology, $1971,77,245-255$.

LOGAN, F. A. Incentive. New Haven: Yale University Press, 1960.

MELVIN, K. B., \& BROWN, J. S. Neutralization of an aversive light stimulus as a function of a number of paired presentations with food. Journal of Comparative \& Physiological Psy chology, 1964, 58, 350-353.

MURRAY, M.. \& NEVIN, J. A. Some effects of correlation between response-contingent shock and reinforcement. Journal of the Experimental Analysis of Behavior, 1967 , 10, 301-309.

PAVLOV, I. P. Conditioned reflexes. Oxford: Oxford University Press, 1927.

WILLIAMS, D, R, \& BARRY, H., III Counterconditioning in an operant conflict situation. Journal of Comparative \& Physiological Psychology, 1969, 61, 154-156. 